opesation. It was during my period as surgeon to this hospital that Mr. T. Smith, then assistant-surgeon, introduced his happy modification of staphyloraphy by the invention of the gag which goes by his name, so that the operation could be performed under chloroform, and it was no longer necessarv to wait till the patient became old enough to assist the surgeon. Like all other improvements, these became the starting-points of others, and the operation is now far simpler and far more successful than it was when I was young. I hope that I may say the same with respect, to the group of malformations included under the general name of "imperforate anus." It is not so very long ago since all children born with imperforate anus were abandoned indiscriminately to death hy miny surgeons; but we now know that it is only a very sinall minority who are absolutely not viable, and that even the most formidable cases-those in which the lower bowel is actually absent-are not altogether without hope of surgical relief; while thore are a large proportion where the rectum comes very near the surface or opens into the vagina, in which entire success can be obtained, and the patient restored to complete health and vigour. I was much interested a few weeks since in examining a woman who, when a little girl, was a patient of mine at this hospital, and on whom, here and at St. Georce's Hospital, I operated several times for the relief of a distressing deformity caused by the rectum opening freely into the vagina. When she first came under treatment, in eally chilhood, the small size of the parts, and the free communication between the rectum aud vavina, caused very great difficulty in effecting a complete separation between the two tubes; and, after this was at length seculed, it seemed at first as if there was no retentive power in the bowel. But this was at length acquired; and, when I last saw her, the parts were in all respects natural, and she was perfectly fit for all the functions of a wife or mother. I mention this case because it was a very difficult, and apparently, at first, a very unsuccessful one; and becau e it shows how completely the rectum may acquire the power of retention even in the absence of the regular splincter; and also because it gives nie an opportunity of recording my opinion that even at the pres $n$ t disy we are not sufficiently active in onr treatment of imperforate anus. Early operation, judiciou,ly $d \rightarrow$ vised, would, I believe, restore many infants to health who are now allowed to die.

I trust that the few examples which I have selected from the specialities of children's surgery have been enough to convince you of the alvantage you may derive in your future professional life from a diligent course of surgical study at this hospital. And there is another consideration, which must increase the interest with which surgeons regard practice on children, namely, the immense amount of good which is done in successful cases. It appears to me a very mistaken view of children's surgical disesses, which attributes them, in auy larser measure, to ineradicable constitutional proclicities. I well remember when the operation of excision of the hip was first introduced, a common arcument against its use was, "What is the good of removing the diseased joint, allowing that to be possible, while it is clearly impossible to remove the strumous constitution on which the disease depends?" these chronic joint diseases depend on a constitutional diathesis, though, no doubt, they are common in strumous children, and are more obstinate in them. But there is no doubt that a large proportion are the result of injury acting on a perfectly healthy constitution, and there can be no do' bt that the removal of the diseased joint is followed by complete and permanent recovery. The dars of my surrical service at this hospital are now remote, and most of my former patiputs have passed out of my observation, but I constautly meet rii h indiriduals on whom I operated here from twenty to twenty-five years ago, and who are still in good health; and I may say that cases of this kind are further useful in negativing the idea which has prevailed rather extensively in the case of the elbow, and, to a great ex. extent, also, in that of the knee, that such operations inflict some anexplained general shock on the limb, and are followed by a general wasting and loss of power. The reverse is certainly the case in successful excisions. The limb gains in power and utility, and, if the patient was quite young at the time of the operation, he will probably soon use it almost as nimbly as the other, and with almost as nuch strength.

But the chief advantages of study in this hospital are to be found in a field which I am not competent to survey; and while I should fail in my duty if I did not point out to you how much there is to be learned in children's surgery, my address would be still more in. adequate if it did not conclude by telling you that all this is but a trifle compared with the paramount necessity, for one who is to become a general practitioner, of familiarising himself with the medical affections of childhood and with their treatment, while he has the unequalled opportunity which this hospital presents to him.
I declare to you seriously that if I had a son who was entering into general practice, I would not permit him to do so without having made a special study of children's diseases any more than of those of women. For the latter, it is unnecessary to go beyond the walls of the hospital to which the student is attarhed. There is, I believe, a department for the study of women's diseases in every hospital to which a medical school is attached. But at none of the general hos pitals is there, nor can there be, an efficient department of children's diseases. Even special children's wards are hardly compatible with the due and economic working of a general hospital-at least, that was the conclusion to which the authorities at St. George's came after a patient trial of the experiment many years ago. Hence the liberal and self-sacrificing offer of the physicians and surgeons of this noble institution to place the rich stores of their experience, and the abundant materials of their daily practice, at the service of the students of our London hospitals, is one which cannot be too highly appreciated. I am glad to see from Dr. Cheadle's speech at the last annual dinner that the lectures during last year were well attended, and that as many as 234 visits were paid by students to the hospital. I hope that the liberal invitation of the staff will, in this and future years, meet with the response it deserves, not less for the sake of the students who will acquire knowledge inexpressibly valuable to them hereafter, than for the sake of the many patients who will benefit by the knowledge so acquired.

With repeatad good wishes for the success of the Hosrital, and for your success in your studies here, I bid you very heartily farewell.

\section{THE VALUE OF DISINFECTANTS,}

Being part of an Address delivered at a Combincd Heeting of the Cambridge, Huntingdon, and East Anglian Branches of

the British Medical Association, at Ipswich, on Friday, July 9ih, 1886,

Bx WILLIAM ALFRED ELLISTON, M.D., Surgeon to the East Suffolk and Inswich Hospital ; Prosident of the East Anglian Branch.

IN association with the management, treatment, and control of infectious diseases, the value of disinfectants is of great practical importance. We all know that disinfection, as ordinarily practised, is little more than deodorisation, or the substitution of a fresh odour, oftentimes unpleasant in itself.

I do not wish to detract from the value of many well-known socalled disinfectants, but their virtues are clealy more prized by the public than by the profession. The public faith in some latent power, which is to purify the sick chamber without free admission of fresh currents of air, should be shaken to its core. The great secret of successful nursing is cleanliness and ventilation, and it is possible to secure these without disinfectants at all, provided there be an abun. dant supply of clean bed-and body-linen. Novertlieless, properly selected disinfectants are valuahle assistants in the preservation of cleanliness and sweet air, but they should be understood and appreciated at their real value, and not with an ignorant belief in their fetish power.

Professor Koch has related in the Fractitioner, of November, $18 \div 2$, some important experiments bearing upon the reliability of disinfectants. He put the ordinary ones to the test in three ways. First to ascertain whether a particular disinfectant is capable of destroying the resting spores of bacilli, which are the most difficult of all forms of life to destroy. No disinfectant can be safely trusted which cannot destroy the developing power of the resting spores. The resting spores of splenic fever were generally used. The second is to ascertain how the disinfectant behaves in regard to more easily destructive fungi, such as yeast, bacteria, bacilli, and micrococci ; and thirdly, to ascerthe development of microain in suitable nutritive fluids.

Carbolic acid, in a 5 per cent. solution, only sufficed to arrest the Coveres after two days, while a 1 per cent. solution was developments of sporili themselves. A solusufficient to destroy, in to check the development of the latter. The tion of 1 in 850 sufficed to chat carbolic acid in oil, or in alcoholic 
solutions, is absolutely without effect on the bacilli and spores. The spores after remaining 110 days and 70 days respectively, in a 5 per cent. solution of carbolic acid and oil, and in alcohol, were repeatedly found intact.

Salicylic acid and thymol showed unsatisfactory results, and even sulphurous acid, under such favourable conditions as are not obtainable in ordinary practice, fails to destroy the whole of the minute living organisms that may be present. Chloride of lime was also incapable in a 5 per cent. solution of weakening the power of the splenic fever spores.

After testing various substances, Koch arrives at the conclusion that the only reliable disinfectants are chlorine, bromine, and corrosive sublimate, and that, to arrest development, only corrosive sublimate, and certain ethereal oils, and allyl-alcohol are to be trusted. Bromine vapours are recommended for confined spaces. Chlorine is a little less satisfactory, but more so than has been supposed. It is comforting, however, to observe that, in corrosive sublimate, we have an invaluable germicide, and that solutions of 1 in 1,000 to 1 in 15,000 are sufficient to kill micro-organism's. A solution of 1 in 1,000 was sufficient to kill the resting spores in ten minutes, and, indeed, simple moistening of the earth with this solution is sufficient to arrest the power of development.

The experiments of M. de la Croix, conducted in a totally different manner, also point to the extreme value of the perchloride of mercury and chlorine.

Professor Konig, of Gottingen, also relates a personal experience of twenty years' experience of the value of fumigation of rooms by sublimate. The method he adopts is very simple. After closely shutting the windows of the infected room, the person who carries the disinfectant sprinkles about fifty or sixty grammes of the sublimate on a coal-shovel, over a glowing firepan, and then quickly leaves the room and locks the door. All chinks must be stopped beforehand. The sublimate evaporates quickly, and the room is now left exposed to the fumes for three or four hours. The door is then opened, and in opening the window, care must be taken to hold a cloth over the nose and mouth. The door is immediately locked again, and the room is aired for several hours, the windows being left oren. The windows are once again shut, and the room is fumigated in the nsual way with sulphur, in order to render harmless the mercury which is still present. Professor Konig states he has never observed any harm to those who carried out this method, nor to the inhabitants of the cleansed room.

Professor Förster, of Amsterdam, also bears testimony to the value of a solution of from $7 \frac{1}{2}$ to 15 grains of sublimate in thirty-five ounces of distilled water, as a perfect disinfectant for the hands after contact with infection, while he regards the usual solution of carbolic acid and water, 2.: per cent., inadequate for the purpose.

It is satisfactory, therefore, to know that we have reliable chemicals that will stand the severe tests of modern investigation. It is still more satisfactory, I think, that boiling water is a perfect aisinfectant. No contagium can resist a moist temperature of $212^{\circ}$ Fahrenheit. Linen and clothes (of the material that will not be injured by boiling) can be perfectly disinfected by that simple process.

At the request of the German Government, Koch and Wolfhurzel experimented upon the comparative disinfecting value of dry heat and steam. 'They reported that, by the direct application of steam at $212^{\circ}$ Fahrenheit for from five to ten minutes, even the virulence of dried anthrax blood was destroyed. Earth-spores, which have a reputation for tenacity of life at high temperatures beyond all others, wero devitalised by fifteen minutes' exposure to steam, while they resisted the action of dry heat for three or four hours at $302^{\circ}$ Fahrenheit.

Dr. Russell, medical officer of Glasgow, says that, during the last ten years, over a million of articles (from persons affected with every kind of contagion known in this country) have passed through the Glasgow laundry, and that he has never known a case of interchanged disease, although the women engaged in the laundry have occasionally suffered from handling the linen before the boiling process. In the disinfection of apartments, care must be taken to burn the collected kust, and thorough domest c cleansing is necessary, but it is clearly iucumbent upon all sanitary authorities to make provision upon a scale adequate to the purpose, to secure steam disinfection in its varied systematic details.

There is ret another sulje $t$ on which I would desire to say a few word:s, and "with which I wil bring these fragmentary remarks upon matters of importance to the living to a close, and that is the disposal of the dead. All sanitarians must, I think, be agreed that for hygienic excellence and cleanlincss, cremation would dispose of the subject; but there are various circumstances and objections which are beyond the questicns of sanitation, and which cannot be dismissed until the growing evil in a rapidly increasing population will necessitate its serious consideration. But I would specially remind those in favour of a continuance of the present Christian rites, that until the time of Charles II, coffins were rarely used in England, and it would be well if we returned to the more simple and more hygienic system of burial then in rogue, and thus secure an earlier and more complete disintegration of the body.

Gentlemen, I beg to thank you for your courteous attention to these remarks upon subjects in which, from the very nature of their calling, we cannot fail to take an absorbing interest.

\section{BRITISH MEDICAL ASSOCIATION,}

\author{
FIFTY-FOURTH ANNUAL MEETING.
}

PROCEEDINGS OF SECTIONS.

\section{SCARLET FEVER IN RELATION WITH THE DISTURBANCE OF IMPURE SUBSOIL AND THE CONSTRUCTION OF SEWERS ; FROM PERSONAL OBSERVATIONS DURING AN EPIDEMIC.}

\section{Read in the Section of Public Medicine at the Annual Mecting of the British Medical Association in Erighton.}

By PHILIP BOOBBYER, M. B.,

Medical Officer of Health to the Basford Sanitary District, South Notts.

I HAVE here a few facts bearing on the propagation of scarlet fever r:corded by me during a series of epidemics which visited my district in South Notts in 1885.

The fever existing only in a few scattered cases over the least populous part of the North-Western (Greasley) Division in December, 1881, gradually and unequally spread, from this date, to the colliery vil. lages of the Erewash Valley and their neighbourhoods until, by the middle of the following March, it had invaded, more or less, almost every hamlet between Selston (north) and Kimberley (south), a stretch of 7 to 8 miles, on the eastern slope of the valley.

In the following February, during the course of this slow extension, two villages in Selston Parish, wide apart from one another, and separated by others, as yet unattacked, from the nucleus of the epidemic, were almost simultaneously invaded to a very general extent, whole families being infected at once. After careful inquiry, I could discover no peculiar facilities of the ordinary kind in the case of either place for the acquisition of the fever to this extent. In paying a visit, however, on one occasion, I was struck by the fact that, at both places, a considerable disturbance of old artificial soil around houses and distribution of midden contents had taken place. In the one case, the ground had been but superficially dug, cleared of rubbish, and manured. In the other, a considerable mass of soil from an old inhabited area has first been removed for the purpose of levelling, and the subsoil then treated as above. I may say that the middens were of the type too often found in such places, being deep, capacious, and leaky.

Contemporary with the scarlatina, enteric fever (a common complaint at all seasons in such districts as mine, and much health depression, with its attendant maladies) occurred in these hamlets. There was no diphtheria, however, and no tendency to epidemic extension of anything but the scarlatina. The mortality was abnormally low, if we accept the average as ten per cent. Exact figures I cannot give, but it could not have exceeded three or four per cent. of those attacked.

After the middle of March, this first epidemic declined at all points, its decline bein naturally most noticeable where its invasion had 